\title{
TRANSITANDO PELO SANTO DAIME: UMA CONSTRUÇÃO NARRATIVA A PARTIR DE ALGUMAS CONVERGÊNCIAS. ${ }^{\circledR}$
}

\author{
Juan Scuro $^{2}$ \\ "Hablale del desplazamiento del punto de vista"
}

\section{Introdução}

A idéia de deslocamento é, dentro do processo de criação de conhecimento antropológico, uma distinção da disciplina cujo leitmotiv tenta ser esse permanente traslado do olhar, do sentir, do pensar, a fim de compreender o Outro. A idéia de deslocamento, chave do pensamento reflexivo, é operada no interior da antropologia através de um processo cognitivo, de uma trajetória do pesquisador em suas iniciações etnográficas. O campo de trabalho que atualmente nos interpela, isto é, o estudo da religião do Santo Daime, fez nos pensar que esse tão prezado patrimônio da antropologia está presente entre os grupos de pessoas com os quais interatuamos. Trata se de, seguindo a Clifford Geertz, "saberes locais" (Geertz, 2003).

A frase com a qual começam estas páginas pertence à Stella, mãe de Ernesto, dirigente de uma igreja do Santo Daime que, enquanto conversávamos, Stella de longe sugeriu ao seu filho "hablale del desplazamiento del punto de vista". Mais uma vez, as aparentes trivialidades do campo, nimiedades as quais às vezes é difícil dar o sentido certo, tornam-se nossos elementos de reflexão mais apropriados se observados e interpretados adequadamente.

O leitor é convidado, através destas páginas, a percorrer uma possibilidade discursiva em torno de alguns temas que começam a ser de interesse no marco da nossa pesquisa sobre a religião do Santo Daime. Aqui desenvolvemos uma mirada à noção de individuo constituída nesta comunidade religiosa tentando fugir, seguindo a Marcio Goldman (1999), à dicotomia tão fortemente ocidental que é a da relação indivíduosociedade. Observando a disposição geográfica das igrejas do Santo Daime nas cidades onde está presente esta religião, isto é, afastadas dos "centros" das mesmas, tentamos construir nossos olhares desde uma perspectiva de fronteira (Mignolo, 1998). Logo, trazemos ao leitor o contexto que permite a compreensão do que é o Santo Daime para

\footnotetext{
${ }^{1}$ Esse trabalho foi apresentado no II Colóquio Individualismo Sociabilidade e Memória (PPGASUFRGS) em Dezembro de 2010.

Agradeço a Jéssica Hiroko pelas correções de língua portuguesa.

${ }^{2}$ Universidade Federal do Rio Grande do Sul, Brasil.
} 
assim passar à discussão em torno do individuo. Vemos, à luz do pensamento de Louis Dumont (1911-1998), Michel Foucault (1926-1984) e Michel Maffesoli, uma sobreposição de aspectos tanto do denominado individualismo quanto do espírito comunitário de que fala este último autor.

Finalmente interpretamos, com ajuda do pensamento de Walter Benjamin (18921940) e de Michael Taussig, uma forma de construir uma narrativa daimista que transite pelas noções até então desenvolvidas. Trata-se então, do começo de uma trilha através do mundo criado pelo Mestre Raimundo Irineu Serra.

\section{Outro ponto de vista}

Nas cidades onde o Santo Daime está presente, as igrejas da doutrina localizamse longe dos centros históricos das mesmas. Colocando um centro nos pontos históricos a partir dos quais algumas cidades vão se expandindo (Praza principal, Catedral, etc.) poderíamos dizer que as igrejas daimistas localizam-se numa periferia. Porém, esta leitura regionalista hegemônica (Bourdieu, 1989) nos desvia de outros centros possíveis de ser pensados. É preciso uma abordagem não dualista que permita olhar o entre. É preciso pensar com Walter Mignolo (1998) uma epistemologia de fronteira que permita relocalizar alguns fenômenos às vezes considerados "longe dos principais centros". O significado do pensamento do semiótico argentino nestas páginas tem a ver com uma proposta intelectual de levar adiante um pensamento de fronteira. É nesse sentido que tem pertinência trazer o seu aporte aqui já que, como veremos no final deste artigo, entendo que esta simetria de experiências, este particularismo ou localismo permite a emergência de novas narrativas. Assim, junto com Michael Taussig e Walter Mignolo nos vemos tentados à construção de novos caminhos discursivos. Este pensamento de fronteiras é, segundo Mignolo, um enramado de historias locais em desenhos globais, é o projeto universal de fragmentação, então a grande tarefa ético-política de hoje e do futuro (Mignolo, 1998).

Pensando nestes termos surge uma inquietude. Qual a particularidade da narrativa daimista? Ou melhor, como construir essa narrativa que transite as margens? Como tratar dialogicamente com a emergência discursiva produzida a partir desta dialética, deste enfrentamento de regiões?

A narrativa em Michael Taussig (inspirado em Walter Benjamin), a fronteira em Walter Mignolo, nos conduz ao relato em Michel de Certeau (1998). Trata-se do relato delinqüente que vive do deslocamento. Trituremos mapas junto a de Certeau para 
construir relatos que transitem novos "entres". Os estreitos limites do espaço euclidiano impõem restrições à experiência narrada, mas com de Certeau é possível transitar novos percursos.

\begin{abstract}
Se o delinqüente só existe deslocando-se, se tem por especificidade viver não à margem mas nos interstícios dos códigos que desmancha e desloca, se ele se caracteriza pelo privilegio do percurso sobre o estado, o relato é delinqüente. A delinqüência social consistiria em tomar o relato ao pé da letra, tomá-lo como o princípio da existência física onde uma sociedade não oferece mais saídas simbólicas e expectativas de espaços a pessoas ou grupos, onde não há mais outra alternativa a não ser o alinhamento disciplinar e o desvio ilegal, ou seja, uma forma ou outra de prisão e a errância do lado de fora (de Certeau, 1998:216).
\end{abstract}

Somos convidados então a percorrer estes interstícios, a construir trajetos.

Partindo desta idéia nos interessa observar alguns elementos vinculados à construção de um individuo imaginado, urbano, que pratica o seu culto num lugar determinado das áreas urbanas nas quais a religião do Santo Daime está presente. O afastamento deste centro urbano tradicional, ponto "por excelência" a partir do qual olhar a cidade, a proximidade com uma paisagem (Simmel, 2009), com uma narrativa visual associada à floresta, produz, nestes indivíduos urbanos, um novo olhar, uma nova imaginação do social, uma nova consciência de si mesmos.

Este triturar mapas tem o ar libertário, emancipado, que é necessário para transitar nas profundezas de novos espaços vividos, de novas sobreposições que o espírito do Daime permite. Na experiência daimista é possível a viagem pelos mundos mais recônditos e desconhecidos, alhures rebeldes de ser encerrados em limites estabelecidos.

\title{
O Santo Daime
}

A religião do Santo Daime teve sua origem na tríplice fronteira entre Brasil, Bolívia e Peru nas primeiras décadas do século XX, quando Raimundo Irineu Serra (conhecido como Mestre Irineu) experimentou o uso da Ayahuasca. Ayahuasca é um dos muitos nomes de uma chá de origem amazônica que vem sendo utilizado com fins religiosos por variados grupos de pessoas e cujo maior conhecimento atual é devido, em parte, ao processo de expansão das chamadas religiões ayahuasqueiras ${ }^{3}$ (Santo Daime,

\footnotetext{
${ }^{3} \mathrm{O}$ conceito de religiões ayahuasqueiras foi estabelecido a partir da formação de um campo de estudo que gira em torno à substância. São vários os trabalhos realizados dentro da temática. Estes estudos abarcam uma grande área de convergência de enfoques disciplinares passando pela história, antropologia, farmacologia, etc.
} 
União do Vegetal, Barquinha) e sua chegada nos centros urbanos. Ayahuasca é o nome mais conhecido para designar a preparação de um chá feito a partir do cipó Banisteriopsis caapi e da folha Psychotria viridis.

Remeto o leitor à literatura citada no pé de página para ter uma melhor compreensão do Santo Daime e poder continuar com os eixos de trabalho aqui pertinentes. Deixo, nas palavras de Luiz Eduardo Soares, sua leitura dos praticantes desta religião.

Indivíduos de camadas médias urbanas, em geral com acesso a bens culturais razoavelmente sofisticados, representativos de trajetórias identificadas, em boa medida, com o programa ético-político moderno típico — não raro com passagens pelo divã psicanalítico e pela militância partidária — e com experiências existenciais que 68 consagrou e resumiu, no imaginário histórico; indivíduos, portanto, "liberados", "libertários", "abertos" e críticos da tradição — sobretudo do "fardo repressivo" das tradições religiosas -, sujeitos exemplares do modelo individualistalaicizante, sintonizados com o cosmopolitismo "de ponta" das metrópoles mais "avançadas", sentem-se crescentemente atraídos pela fé religiosa, pelos mistérios do êxtase místico, pela redescoberta da comunhão comunitária, pelos desafios de saberes esotéricos, pela eficácia de terapias alternativas e da alimentação "natural". Meditação, contemplação, busca de "equilíbrio consigo mesmo, com a natureza e com o cosmos" encontram ênfase inusitada e contrastam com o declínio de posturas rebeldes ativas, antes valorizadas. (Soares, 1994:2)

Esboçamos algumas idéias que começam a surgir a partir da nossa inserção no campo daimista. O Santo Daime, como foi dito por vários dos seus integrantes, é uma religião cristã. Acrescentaríamos que se trata de uma grande convergência de diferentes tradições religiosas. Isto é visível em vários níveis diferentes; numa primeira e rápida instância a partir dos elementos iconográficos que a doutrina tem. Nas igrejas do Santo Daime às quais tive oportunidade de entrar aparece uma grande quantidade de objetos religiosos pertencentes às mais variadas tradições religiosas ou culturais. Numa igreja do Santo Daime em Porto Alegre pude visualizar, rapidamente, a seguinte iconografia: mirando para a porta da igreja, a poucos metros dela, numa pequena casinha sobre o

Recomendo ao leitor interessado:

Labate, B. e Sena, W. (Orgs.). O uso ritual da ayahuasca. Mercado de letras. São Paulo. 2002

Labate, Beatriz. A reinvenção do uso da ayahuasca nos centros urbanos. Mercado de letras. SP. 2004

MacRae, Edward. Guiado pela Lua. Xamanismo e uso ritual da ayahuasca no culto do Santo Daime. Brasiliense. SP. 2002

Labate, B., Goulart, S., Fiore, M., MacRae, E., Carneiro, H. (Orgs.). Drogas e Cultura. Novas perspectivas. EDUFPA. Salvador. 2008.

Groisman, Alberto. Eu venho da floresta: ecletismo e práxis xamanica daimista no Céu do Mapiá. Dissertação de mestrado. UFSC. 1991

Sítios web:

www.neip.info

www.afamiliajuramidam.org

www.santodaime.org 
chão, uma imagem de São Miguel cuidava do entorno. O chefe do exército de Deus tem o seu lugar de adoração nesta Igreja do Santo Daime. A poucos metros dela e diante da porta da igreja, se encontra uma grande cruz de dois braços, um dos principais símbolos do Santo Daime. Muitas cruzes de seis pontas, ou salomônicas, podem ser vistas dentro da igreja assim como nos uniformes dos fardados. Neste último caso, onde também aparece a águia acima da Lua. Segundo as interpretações, o Mestre Irineu haveria dito que para entender o símbolo é preciso tirar o acento da águia, sendo então que a-guia é a Lua. Fotos de Jesus Cristo, do Mestre Irineu, do Padrinho Sebastião (fundador da linha denominada CEFLURIS -Centro Eclético Fluente Luz Universal Raimundo Irineu Serra- que inclui a maior parte das igrejas fora do estado originário do Acre) decoram a igreja em cada parede e no altar que fica no centro.

Toda esta variedade converge a um único centro que consegue articular estas diferentes tradições numa nova manifestação religiosa. Esse mesmo centro da igreja onde hoje está o altar foi, antes da construção da igreja, o ponto central do círculo onde os cavalos são domesticados. A "energia" do passado desse ponto central da igreja é conhecida pelos daimistas que participaram da construção da mesma.

Seguindo a Michael Taussig e o seu trabalho de interpretação das narrativas do terror produzidas pelo choque cultural na primeira década do século passado a partir da exploração da borracha na área amazônica, vemos o encontro de dois espaços da morte (Taussig, 1993).

Aqui, interessa dar conta da pluralidade de caminhos que convergem num espaço e num tempo determinados, é dizer, a Amazônia das primeiras décadas do Século XX. O que possibilitou a origem do Santo Daime (entre outras coisas) tem sua origem no processo de exploração da borracha descrito por Taussig. Assim, produto do mais voraz capitalismo característico daquela época, convergem na área amazônica, como se fosse um centro de atração, pessoas das mais diversas origens culturais, sociais e religiosas. Um saber ameríndio milenário (vegetalismo, naturalismo, cura xamanica; em definitiva, um dos espaços da morte dos que fala Taussig) encontra-se com o espírito explorador, procurador dos maiores benefícios com os menores custos, lógica do capitalismo selvagem de finais do século XIX e princípios do XX.

Vemos nas palavras de Thiago, fardado daimista há vários anos, o que queremos disser com a convergência de tradições religiosas no Santo Daime. 
O Mestre [fundador Mestre Irineu] quando ele começou, ele colocou que o centro era livre, era a máxima, o centro é livre, ou seja, todas as religiões elas teriam ali uma, um ambiente desestresado e ao mesmo tempo uma possibilidade de sincretizarse, de formar uma coisa hibrida (...) porque o daime ele é uma religião, ela é cristã, a base dela é cristã, só que ela é um hibrido e ai ela vai ter as culturas afro brasileiras, ela vai travar o momento de ruptura da cultura rústica brasileira, no momento de modernização da sociedade e da saída rural para a interação urbana. Então o daime é a primeira religião ayahuasqueira urbana, a primeira vez que se formou um grupo no máximo o que se tem da antropologia ayahuasqueira assim, que vai estudando os grupos ayahuasqueiros se fazer no máximo com 30 pessoas os rituais (Thiago).

Lembrar então a característica eclética e o uso ritual do enteogeno ${ }^{4}$ ayahuasca. Wilton, o dirigente da igreja do Santo Daime em Porto Alegre descrita acima manifestou em varias ocasiões o que a produção bibliográfica sobre o tema não se cansa de repetir: "A ayahuasca é um enteogeno, isso não tem nada ver como droga ou alucinógeno". Não se trata de alucinar, mas sim de incorporar o poder da planta, trata-se de uma experiência espiritual.

Poderíamos resumir esta apresentação do Santo Daime contextualizando-o dentro do trabalhado por Ari Pedro Oro (1989) sobre o messianismo amazônico. Na mesma época e área geográfica que Taussig (década de 1970 e primeiros anos de 1980, Amazônia da fronteira Brasil-Colombia-Peru), Ari Oro identifica, descreve e analisa os movimentos messiânicos emergentes. Vemos a presença destes múltiplos fatores que intervém na produção destas manifestações religiosas. Assim, pensando com Oro, incluímos a origem do Santo Daime dentro dos movimentos messiânicos estudados pelo antropólogo brasileiro.

O próprio hino do Mestre Irineu que fala de doutrinar o mundo inteiro, e esse doutrinar o mundo inteiro não é num sentido pejorativo, é num sentido de possibilitar a ida dos outros ao Santo Daime. Porque o Santo Daime é para todo o mundo, mas nem todo mundo é para o Santo Daime. Isso o Mestre Irineu já falava. Ele queria que simplesmente as pessoas pudessem encontrá-lo onde quisessem (Thiago).

\section{O mais importante é o cuidado de si}

As palavras deste subtítulo foram pronunciadas pelo dirigente duma igreja do Santo Daime ao terminar um ritual. E prosseguiu: “o mais valioso são vocês mesmos".

\footnotetext{
${ }^{4} \mathrm{O}$ termo enteogeno foi utilizado por Robert Gordon-Wasson em 1979 para se referir ao estado espiritual de "Deus-dentro", significado etimológico do termo. Desta forma se elimina o uso de termos como droga ou alucinógeno para nos referir a estas substâncias utilizadas em contextos rituais. Em: MacRae, Edward "El Santo Daime y la espiritualidad brasileña" Abya-Yala. Quito. 2000, o autor desenvolve em extenso a origem do uso deste termo.
} 
Vejamos como chega Thiago ao Santo Daime para ter um ponto de partida nestas reflexões.

Vou te dizer que para mim é uma coisa muito interessante porque eu ando num caminho espiritual há uns quatro cinco anos, há quatro anos que sou vegetariano, não bebo nenhuma bebida alcoólica nada, então antes de ser daimista já tinha essas praticas e eu era, eu sou devoto de Shiva, sou shivaista, então entrei pela linha de oriente, muita meditação...eu sou professor de yoga e aí fui, o espiritual é muito presente. E as plantas de poder (...) todas essas de poder o caminho, chamam guias...sempre me atraiu muito e a ayahuasca também. E aí eu fui, eu sempre fui consagrar as medicinas dentro dos rituais xamanicos e um dia resolvi ir no Santo Daime e ai fui no Santo Daime e não gostei muito cara, aquela coisa dentro da igreja, a primeira vez foi na igreja do Cantagalo faz quatro anos, e ai eu fui lá e não gostei muito, dentro da igreja, queria ficar na floresta, olhando os seres da floresta...e essa é minha historia, a meditação sozinho na floresta escura, e ai quando cheguei tomei o daime e não gostei muito mas foi passando o tempo e uma coisa que foi o básico que me chamou, foi a caridade, eu sempre viajei muito, botei a mochila nas costas, fui para o Chile fui pela America um pouco de carona, e ai eu sempre fui uma pessoa, sempre fui militante de esquerda, sou militante do PSOL, um partido de esquerda aqui em porto Alegre, do Brasil, e ai sempre tive essa missão da caridade, do socialismo, da sociabilidade e ai fui viajando e conhecendo muito o caminho espiritual, muitas comunidades espirituais, comunidades de gente que vivia de luz, comunidade de gente afro, oriental, Hare Krishna, comunidade xamanica, comunidades indígenas propriamente dita, e ai um dia chegando em Minas Gerais me fui para um encontro que é o encontro de comunidades alternativas e ai eu cheguei lá e tudo o que eu vi, o poder da fé, o poder da...de todos os maiores poderes o que tocou meu coração foi o poder da caridade. E esse ouvi num padrinho do santo daime que oferecia para todo mundo, a pessoa chegava na casa dele e ele já estava com um prato de comida na mão e um copo de suco recém feito esperando a pessoa. E ai tocou muito meu coração, na época eu tinha dreads fazia dois anos que não cortava...e eu cheguei e aquele cara me tratou tão bem, sem preconceito nenhum, eu acostumado a preconceito de mochilero, dentro da própria faculdade eu tinha que quebrar barreira, mesmo sendo um cara que sempre estudou muito, sempre gostei muito da historia, eu sempre fui engajado com pesquisa (Thiago).

Mais adiante, e trazendo elementos do que queremos discutir aqui, Thiago disse:

Todo mundo que botou a estrela de Salomão no peito tem a mesma, o mesmo, a mesma patente no exercito da rainha da floresta. O exercito da rainha da floresta, então a mesma patente. Antigamente, no tempo do Mestre tinha diferenciação, estava... só que depois ele tirou. Ali dentro é para todo mundo ser igual, tem um hino que fala, 'todos que olharem para ela tem o mesmo valor' ou seja, todo mundo igual, na mesma. Porque o grande lance do Daime é a vida em comunidade e a compreensão de irmandade cristã. (Thiago)

\section{E continuando a conversação disse:}

Isso também é um estudo muito interessante, a noção de irmandade cristã dentro da doutrina do santo daime que se assemelha muito com a noção das comunidades primitivas proto cristãs, se compara muito, tem muita similaridade entre umas e outras. O padrinho Sebastião ele queria isso, ele queria uma comunidade estilo nova Jerusalém. Uma cidade santa. (Thiago)

Louis Dumont (1911-1998) faz um interessante percurso histórico através da noção de individuo, começando com o que ele denomina indivíduo-fora-do-mundo 
inspirado no modelo de renúncia ao mundo do individuo indiano. Ele visualiza este modelo de renúncia, de afastamento do mundo por parte do indivíduo indiano nos primeiros cristãos. Assim, através da história, se produz uma transformação do indivíduo até a nossa concepção de indivíduo moderno. Diz Dumont:

\begin{abstract}
Algo do individualismo moderno está presente nos primeiros cristãos e no mundo que os cerca, mas não se trata exatamente do individualismo que nos é familiar. Na realidade, a antiga forma e a nova estão separadas por uma transformação tão radical e tão complexa que foram precisos nada menos que dezessete séculos de historia cristã para completá-la, e talvez prosiga ainda em nossos dias. A religião foi o fermento essencial, primeiro, na generalização da fórmula e, em seguida, na sua evolução (Dumont, 1985:36).
\end{abstract}

Vejamos, pois, em que consiste este "semente" do individualismo dos primeiros cristãos para compreender o individualismo moderno, ou melhor dito, aproximarmos a uma idéia de indivíduo daimista. O elemento destacado deste primeiro individualismo de que fala Dumont tem a ver com a libertação produzida a partir do afastamento do mundo. Não se trataria então, segundo Dumont, de intentos de mudar o mundo, mas antes, de se mudar a si mesmos. Isto estaria presente nos movimentos sectários dos primeiros cristãos. É no modelo de renúncia ao mundo, de afastamento dele que o indivíduo encontra uma possibilidade de construção de si mesmo. É preciso o abandono do mundo para alcançar a libertação.

Este indivíduo emancipado que alcança uma transcendência pessoal (indivíduosfora-do-mundo), em união com outros indivíduos na forma de comunidade é segundo Dumont, uma fórmula do cristianismo. Assim, estes indivíduos caminham juntos na terra, mas com os seus corações no céu. (Dumont, 1985).

Este modelo de individualismo que Dumont estuda nos primeiros cristãos estaria mais próximo ao do renunciante indiano que ao próprio do mundo contemporâneo. Não existe uma intenção de mudar o mundo neste modelo de afastamento, de renuncia ao mundo, e seria esta uma diferencia importante respeito a nós mesmos que acreditamos ter adaptado esse mundo às nossas próprias necessidades (Dumont, 1985).

Até aqui, e seguindo a Dumont, poderíamos achar algum tipo de empatia com o que é manifestado por algumas pessoas praticantes do Santo Daime com relação à ênfase colocada no desenvolvimento espiritual e a referência feita a esse modelo de indivíduo localizado nos primeiros cristãos. 
Embora Dumont faça a comparação dos primeiros cristãos a partir do modelo indiano, é preciso trazer em consideração os elementos provenientes do mundo grego que Michel Foucault coloca.

Vejamos com Michael Foucault esse ponto, para compreender os elementos do desenvolvido até agora. Foucault nos convida a observar o mundo helenístico para detectar a preeminência do cuidado de si.

O grande pensador francês denomina de individualismo o espaço que o mundo helenístico e romano conferia aos aspectos privados da vida. Fazendo uma revisão histórica através de pensadores da época, Foucault identifica uma significativa importância no que respeita à conduta pessoal e ao interesse que se tem por si próprio (Foucault, 1985).

Foucault diferencia três aspectos deste "cuidado de si": por um lado a atitude individualista, isto é, a atribuição ao individuo de valor absoluto, de singularidade. Por outro lado o valor outorgado à vida privada, às relações familiares e patrimoniais. Por último, a intensidade das relações consigo mesmo, tomar-se como objeto de conhecimento para transformar-se e purificar-se (Ibid).

Em Michel Foucault, a perspectiva adotada na análise deste individualismo dos primeiros cristãos ao que estamos fazendo referência, tem um caráter mais detalhado ao distinguir o seguinte:

\footnotetext{
Há sociedades ou grupos nos quais a relação consigo é intensificada e desenvolvida sem que por isso, e de modo necessário, os valores do individualismo ou da vida privada encontrem-se reforçados; o movimento ascético cristão dos primeiros séculos apresentou-se como uma acentuação extremamente forte das relações de si para consigo, mas sob a forma de uma desqualificação dos valores da vida privada; e, ao tomar a forma do cenobitismo, manifestou uma recusa explícita daquilo que podia haver de individualismo na prática da anacorese (Foucault, 1985:48).
}

Nestas palavras de Foucault vemos alguns elementos que nos conduzem à análise desse cuidado de si desde uma forma de socialização presente no cenobitismo de que o autor fala. É este um ponto de destacada importância no que queremos problematizar aqui, isto é, uma sociabilidade a partir do cuidado de si, ou, em outras palavras, o cuidado de si como forma de sociabilidade.

Diz Foucault: "O cuidado de si -ou os cuidados que se tem com o cuidado que os outros devem ter consigo mesmos- aparece então como uma intensificação das relações sociais" (Ibid, 58). E mais adiante, "O cuidado de si aparece, portanto, 
intrinsecamente ligado a um 'serviço de alma' que comporta a possibilidade de um jogo de trocas com o outro e de um sistema de obrigações recíprocas" (Ibid, 59).

A ênfase colocada no valor do cristianismo, e mais especificamente, nas comunidades dos primeiros cristãos, nos conduziu a uma leitura destas narrativas a partir do que Louis Dumont e Michel Foucault trabalham, desde diferentes perspectivas, em torno da questão da formação desta ideologia do individualismo, esta problematização do sujeito.

Esta discussão na França dos anos oitenta inclui o pensamento de Michel Maffesoli. Posterior aos já citados trabalhos de Dumont e Foucault, Maffesoli escreve em 1988 sobre o declínio do individualismo. Vejamos como estas idéias tencionam com o até aqui desenvolvido. Não acho contraditório refletir com Maffesoli à luz do pensamento de Dumont e Foucault para o caso que estamos trabalhando. Concordamos com o autor de "O tempo das tribos" (1988) quando afirma que:

\begin{abstract}
De toda maneira, sob qualquer denominação que se lhe dê (emoção, sentimento, mitologia, ideologia) a sensibilidade coletiva, ultrapassando a atomização individual, suscita as condições de possibilidade para uma espécie de "aura" que vai particularizar tal ou qual época: como a aura teológica na Idade Média, a aura política no século XVIII, ou a aura progressista no século XIX. É possível que se assista agora, à elaboração de uma aura estética onde se reencontrarão, em proporções diversas, os elementos que remetem à pulsão comunitária, à propensão mística ou à perspectiva ecológica (Maffesoli, 1998:20).
\end{abstract}

Essa aura estética, essa pulsão comunitária de que fala Maffesoli possibilita, e este é o maior potencial observado na doutrina do Santo Daime, um desenvolvimento de um indivíduo que encontra nesta doutrina religiosa um espaço de convergência de outros Outros em procura de um eu. Não se trata de um jogo de palavras; trata-se de uma perspicaz estratégia de adaptação que o Santo Daime estabelece, fundada no seu próprio ecletismo, conseguindo articular as duas dimensões, tanto a do eu quanto a de nós. Mas não se trata de um nós enquanto projeto político identitário como o próprio Maffesoli assinala; trata-se de um nós na forma de muitos eu, perto de uma dinâmica de ajuda mútua. No Santo Daime converge, como tantas outras coisas, a possibilidade da construção de um individualismo baseado num espírito comunitário. No Santo Daime, da mesma forma que nas dinâmicas grupais de ajuda mútua, cada indivíduo tem um lugar para se achar, reconhecer e desenvolver suas potencialidades conforme é consciente do caminho percorrido pelo "soldado do exército de Deus" que caminha a seu lado. Concordamos com Maffesoli quando afirma: 
Essa solidariedade orgânica se expressa de mil maneiras e, certamente, é neste sentido que devemos interpretar o ressurgimento do ocultismo, dos cultos sincretistas e, mais particularmente, a importância conferida ao espiritualismo ou à astrologia (Ibid. 20).

$\mathrm{Na}$ comunidade de destino (utilizando o conceito do próprio autor) que estudamos aqui, isto é, na comunidade do Santo Daime, convivem as duas possibilidades de manifestação da mesma. Como assinala Maffesoli, a comunidade de destino pode exprimir-se tanto através do quadro de um projeto racional, político, quanto da sensibilidade coletiva. No primeiro caso, a história, a política e a moral são colocadas numa linha de evolução, de problemas que se colocam para serem resolvidos ou tentar resolver. No segundo caso, o destino, a estética e a ética são colocadas sob o instante eterno que se esgotam de forma trágica (Maffesoli, 1998). É evidente que no Santo Daime temos muito deste segundo aspecto, desta segunda possibilidade de expressão da comunidade de destino. Porém, existe no Santo Daime uma intenção moralizante, um projeto de pessoa a ser construído através de uma vigilância moral. $\mathrm{O}$ indivíduo não chega ao Daime somente para vivenciar em comum, atraído por uma sensibilidade orgânica. Ou, sendo esse o caso, ele volta a se inserir no contexto social com um dever moral de construção individual. Manifestou Ernesto: "el Daime como religión cristiana te exige un compromiso con uno mismo, con dios, con la vida y con los semejantes, te exige una cierta prolijidad en la vida".

Vemos então a possibilidade de uma sensibilidade compartilhada, de um espírito comunitário no sentido de uma comunidade emocional ao tempo que, permitindo a exaltação do eu, colocando, não o projeto político como o valor supremo, mas a construção moral do indivíduo. Nas palavras de outros daimistas:

Cada pessoa que chega tem alguma coisa a agregar, e essa é uma coisa chave porque dai é que tem a universalidade ou o Centro Eclético do que o mestre falava, esse ecletismo cultural e religioso é a chave do Santo Daime. (Thiago) porque no daime todo mundo é o xamã iniciante ou xamã em potenciante, ou seja cada um vai descobrir essas potencialidades de viajar no astral e de se auto curar e de aprender com a viagem com a cura dos outros, então cada um vai tendo potencialidades diferentes. (Thiago)

Quanto mais responsáveis mais livres, não é ao contrario, é assim mesmo, a responsabilidade é a forma de ter a maior liberdade (Cesar).

O mais importante é deixar a um lado todos os preconceitos (...) há nove anos que sou fardado e não me arrependo de nada, o Daime me ajudou muito. (Cesar) 


\section{A construção de uma narrativa}

Pensando com Michael Taussig a possibilidade da construção de uma nova narrativa sobre o terror, levo a sua proposta à construção discursiva do Santo Daime em relação ao individuo. Vimos até aqui, ajudados pelo pensamento de três franceses preocupados com a questão do sujeito e o grupo no qual estes mantém relações, uma convergência no Santo Daime do que poderíamos denominar como elementos de individualismo (Dumont) com uma forte tendência comunitária (Maffesoli).

Como é articulada esta imbricação de aspectos só em aparência contraditórios?

Diz Taussig:

Com a conquista e a colonização européia, esses espaços da morte se misturam em um fundo comum de significantes essenciais, ligando a cultura transformadora do conquistador à do conquistado. No entanto, os significantes estão estrategicamente deslocados em relação àquilo que eles significam (Taussig, 1993:27).

Interpreto estas palavras como querendo criar um espaço de novos significantes, um deslocamento que possibilita o percorrido de uma nova narrativa, uma montagem com espaços a ser preenchidos. Numa leitura de Taussig entendo este espaço da morte como um espaço de transformação.

No entanto este espaço da morte é proeminentemente um espaço de transformação: através de uma experiência de aproximação da morte poderá muito bem surgir um sentimento mais vívido da vida; através do medo poderá acontecer não apenas um crescimento de autoconsciência, mas igualmente a fragmentação e então a perda de autoconformismo perante a autoridade (Ibid. 29).

Poderíamos fazer uma dupla leitura, ou melhor, uma única leitura em dois níveis diferentes, o do indivíduo e o da comunidade.

A experiência de beber ayahuasca é uma experiência de morte. Junto com o sonho, esse estado da vida que nos permite voltar e construir novos olhares de nós mesmos, a ayahuasca faz perceber-nos desde outro ponto de vista. Essa experiência de morte se traduz numa forma de estar muito vivo. A minha própria experiência, e a de muitas pessoas que fizeram uso do chá, é a de estar "perto" da morte. Em poucos minutos se produz um efeito antagônico no organismo que vai desde a completa impossibilidade de mover o corpo até a mais plena sensação de paz, força e harmonia. É aqui então a experiência de aproximação à morte que, lembrando a Taussig, produz um sentimento mais vívido da vida. Isto no nível individual. Só para enriquecer estas argumentações com o que o próprio Taussig levanta no seu trabalho de campo no 
Putumayo, os convido a percorrer as afirmações de Antonio Benavides, curador e conhecedor dos poderes das plantas, com quem Taussig mantivera uma relação de amizade durante o seu trabalho.

As plantas não são como os remédios que se compram nas farmácias. Elas encerram um mistério e é preciso rezar e concentrar-se antes de as colher e usar, garantiu-me Antonio (Ibid, 281).

E continua Antonio falando da ayahuasca:

Ele encerra noventa por cento do poder do reino das plantas! (...) mas é preciso ser um grande conhecedor para poder trabalhar com ele (...). O yagé tem esse grande poder graças aos desígnios da Providencia Divina e transporta o espírito para qualquer lugar do espaço... (Ibid, 281-282).

Prossegue Taussig:

\begin{abstract}
Quando ele tentava dar mais explicações sobre o yagé, referia-se ao modo como ele abria o corpo, despertava-o por meio da coordenação das forças corporais com a das estrelas e dos minerais, de tal modo que a pessoa se fundia com o globo, o Universo. No entanto, dizia ele, havia um problema: o capitalismo está destruindo o globo, e os líderes do mundo o estão contaminando. Essa gente, disse ele, empregando a palavra pueblo, está confusa e nos arruína. Agora já não existem mais laços que nos liguem. 'Tudo se deve às grandes potências, quando construíram as armas de guerra, as armas bélicas. Alegavam que era para a defesa, mas na realidade era para destruir seus próprios irmãos e irmãs que, um dia, poderiam servir. E não foi só Vietnã', acrescentou, 'já está se aproximando daqui' (isto foi em 1976) (Ibid. 282).
\end{abstract}

Este último trecho é o que nos leva ao segundo nível de leitura do qual falava acima, o nível da comunidade. Partindo dessa necessidade de ter um objeto odiado que Taussig nos lembra, se produz um "diálogo", um novo choque de espaços da morte, à interna do enramado cultural onde o Santo Daime se desenvolve.

Afirma Luiz Eduardo Soares:

Inúmeros motivos explicam a tendência do campo a ser polarizado pelo Santo Daime; vale dizer, explicam não só sua força de atração, como de repulsão. Se, hoje, o Daime ocupa um lugar sui generis, é porque encanta, recruta, fascina, mas também inquieta, choca, mobiliza polêmicas e enseja críticas radicais (Soares, 1994:5).

Constitui-se assim uma dialética discursiva interna-externa em torno ao Santo

Daime. O que quis com esta montagem foi deixar um espaço aberto à criação desta narrativa, à emergência de uma memória que gostaria de mostrar da seguinte forma: 
“O narrador” de Walter Benjamin (1892-1940) nos faz pensar de imediato na questão da memória. A memória em Benjamin é conhecimento possível de ser transmitido através da narrativa. $\mathrm{O}$ autor identifica no advento da imprensa, e por tanto, na possibilidade da reprodutibilidade do romance, a morte da narração. Com a imprensa da modernidade colocamo-nos num mundo de informação que reprime a narrativa.

A rareia na arte de narrar na modernidade é produto da difusão da informação.

Diz Benjamin,

Cada manhã recebemos notícias de todo o mundo. E, no entanto, somos pobres em histórias surpreendentes. A razão é que os fatos já nos chegam acompanhados de explicações. Em outras palavras: quase nada do que acontece está a serviço da narrativa, e quase tudo está a serviço da informação (Benjamin, 1993:203).

Se esta fórmula nos parece clichê no século XXI, é graças aos aportes de pensadores como Walter Benjamin ou Maurice Halbwachs (1877-1945) que pensaram nos inícios do século passado sobre estas questões.

Benjamin nos ensina que:

é no momento da morte que o saber e a sabedoria do homem e sobretudo sua existência vivida -e é dessa substância que são feitas as histórias- assumem pela primeira vez uma forma transmissível (Ibid. 207).

Benjamin assinala que o vínculo que a burguesia moderna estabelece com a morte limita a narrativa. Antigamente era costume morrer em qualquer quarto da casa, e é nesse momento da morte que o conhecimento em forma de narrativa toma forma e pode ser transmitida. Nesse afastamento contemporâneo da morte, onde a morte é (valha o paradoxo) vivida em lugar determinado, hospitais longe da casa, reprime-se a narrativa.

É da morte que surge a narrativa.

Diferente do que acontece hoje com a burguesia e o seu vínculo com a morte, no Santo Daime participamos de um "morrer juntos". Todo daimista pode receber um hino que virará parte do acervo sagrado da doutrina. Claro que existem hinos de maior prestigio que outros, assim, o hinário recebido pelo Mestre Irineu é fundamental e o mais respeitado dentro da doutrina. O que quero assinalar com isto é que, neste espaço de comunidade, nesta prática ritual, os participantes são convidados a "morrer juntos". Assim, a morte, à diferença da lógica burguesa que Benjamin identifica estabelecendo um vínculo de afastamento, é, no Santo Daime, não só bem-vinda, mas fator, motor de 
mirações ou ensinamentos que possibilitam a reatualização permanente da doutrina. É esse o poder do xamã em potência do que falava Thiago acima.

Problematizemos estas questões com o pensamento de Danièle Hervieu-Léger. A autora adota, a nosso modo de ver, uma postura benjaminiana quando diz: "La afirmación del sujeto autónomo, el avance de la racionalización que disipa los 'cosmos sagrados' y el proceso de diferenciación de las instituciones implican el fin de las sociedades memoria" (Hervieu-Léger, 2005:208). E continua:

La trayectoria de la secularización y de la desaparición de la memoria total de las sociedades sin 'historia' ni 'pasado' coinciden por completo, al tiempo que certifica el avance de la racionalización, la dislocación de las estructuras de plausibilidad de la religión en el mundo moderno sigue las fases sucesivas de la fragmentación de la memoria colectiva (Ibid.).

A autora, seguindo a Halbwachs, afirma:

Esta pérdida de profundidad de la memoria colectiva que Halbwachs vinculaba al avance de la moderna economía industrial es más sensible incluso en el universo de imágenes que caracteriza a aquellas sociedades en las que se impusieron los medios más sofisticados de comunicación; la sobreabundancia de la información disponible en todo momento tiende a hacer desaparecer las continuidades significativas que hacen que esta información sea inteligible (Ibid. 209).

Vemos uma memória fragmentada. Uma memória feita pedaços. Mas toda religião, afirma Hervieu-Léger, implica uma mobilização de uma memória coletiva. Assim, observamos na dinâmica do Santo Daime a possibilidade de adscrição a uma linhagem de memória. Esta linhagem, que começa de alguma forma nos primeiros cristãos aos que fizemos referencia neste texto e, passando pelos grandes mestres da doutrina como Irineu, Sebastião, etc. é permanentemente atualizada a partir da possibilidade de cada membro da comunidade contribuir com seus próprios hinos.

Estabelece-se então a filiação a uma memória religiosa que, como mostra Halbwachs, tem um lócus geográfico especifico.

Mas toda a religião tem também sua história, ou antes, há uma memória religiosa feita de tradições que remontam a acontecimentos geralmente muito distantes no passado, e que aconteceram em lugares determinados. Ora, seria muito difícil evocar o acontecimento se não imaginássemos o lugar que conhecemos geralmente não porque o vimos, mas porque sabemos que existe, que poderíamos vê-lo, e que em todo o caso, sua existência está garantida através de testemunhas. É por isso que há uma geografia ou uma topografia religiosa (Halbwachs, 2004:164). 
Os acontecimentos produzidos nas primeiras décadas do século passado na floresta amazônica objetivam este lócus do qual fala Halbwachs. "Sem dúvida, nem todos os fiéis podem ir em peregrinação a Jerusalém, e contemplar com seus próprios olhos os lugares santos. Mas, basta que os imaginem e que saibam que sobrevivem: ora, jamais duvidaram deles" (Ibid.165). Céu do Mapia, comunidade daimista na Amazônia onde se localiza a Igreja Matriz da doutrina, é pensado como esse lugar sagrado, cidade santa da que nos falava Thiago acima.

A mesma área geográfica da Amazônia produtora de borracha nos inícios de Século XX, vítima da conquista, da colonização descrita por Taussig, é ao mesmo tempo o lugar de encontro, de choque dos espaços da morte. Uma espécie de efeito de atração, motivado pela exploração da borracha, gera uma convergência de saberes e, como efeito contrario, uma rápida expansão de novos saberes já misturados e reapropriados. São nessas mesmas primeiras décadas estudadas por Taussig e Oro, é esse mesmo centro de gravidade atraente de diversidades o que possibilita, num movimento de atração e repulsão, a construção de uma nova narrativa necessariamente eclética.

Da mesma forma, esses centros das igrejas aos quais os fiéis do daime apontam sua concentração a cada repetição dos rituais, produzem o efeito seguinte de expansão da doutrina e dos saberes da floresta a novos horizontes. O exército da floresta que o Santo Daime adoutrina em cada hino, em cada ingestão do chá milagroso, se espalha num novo contexto urbano onde é possível a produção de novas formas de estar no mundo. Desde que é possível que a pessoa que experimenta ayahuasca "vire raiz", como é descrito em múltiplas narrativas de fieis do Daime ou usuários do chá; e lembrando o perspectivismo ameríndio descrito por Eduardo Viveiros de Castro (1996), é possível imaginar um individuo habitante de múltiples mundos, de múltiples tempos e espaços.

Da mesma forma que o ponto central da igreja a que fiz referência nestas páginas, aquele ponto central que, como me contaram alguns daimistas que participaram da construção da igreja, já foi centro domesticador de cavalos, produz, algum tempo depois, soldados do exército da floresta que voltam ao mundo urbano também domesticados pela doutrina do Santo Daime.

\section{Conclusão}

Tentamos construir um olhar ao Santo Daime a partir do desdobramento dos eixos temporal e espacial. Estas páginas querem ser o inicio da construção de uma 
temporalidade e de uma espacialidade daimista. Temos muito por fazer ainda em relação à interpretação da cosmologia daimista segundo a perspectiva que aproximamos aqui. O propósito deste artigo foi refletir, na medida do desenvolvimento atual do nosso trabalho com o Santo Daime, à luz da própria natureza polimorfa e infinitamente adaptativa desta religião. O Santo Daime consegue se expandir e adaptar rapidamente aos mais diversos contextos culturais. Assim o demonstra o seu percorrido, em menos de um século, desde a mais profunda Amazônia até o Japão. Os elementos naturais com os quais preparar o chá estão presentes em todos os continentes. A ayahuasca pode ser comprada pela internet. O Santo Daime, como o capitalismo, consegue, graças a seu ecletismo, se desenvolver estratégica e rapidamente pelo mundo.

A problemática do deslocamento é trabalhada desde a possibilidade de construção de uma narrativa daimista. O deslocamento, o perspectivismo ameríndio (Viveiros de Castro, 1996), a epistemologia de fronteira (Mignolo, 1998) nos levaram à procura de um fio de memória.

Vimos, com Dumont, Foucault e Maffesoli uma problematização em torno à questão do individuo. Assim, tomando os próprios termos dumontianos, poderíamos dizer que no Santo Daime encontramos uma proposta de constituir indivíduos-fora-domundo-no-mundo. Dumont e Foucault nos mostraram algumas idéias em torno àquela noção de individuo nos inícios da nossa era. Maffesoli nos mostrou uma tendência comunitária no final do século XX. A nossa observação, participação, leitura e diálogo com o mundo daimista nos conduz a pensar esta possibilidade de um indivíduo preocupado com o cuidado de si, um indivíduo espiritual dentro de uma sociabilidade comunitária. Tudo isto inserido em contextos urbanos, mas num lugar particular desses centros urbanos. Num lugar que remete àquelas paisagens da floresta, um lugar geográfico que necessariamente produz o deslocamento. Trata-se, com Maffesoli,de um sair de si, não de um sair de si para se perder no conjunto do grupo, mas sim para voltar ao próprio eu.

Por outra parte, esta superposição nos conduz a pensar à luz de uma narrativa que se constrói a partir de uma memória coletiva localizada geográfica e espiritualmente. É essa noção de indivíduo que possibilita o diálogo com esta memória, este jogo do tempo permite simultaneamente a permanente adaptação da doutrina. Porém, a repetição sistemática do ritual na forma mais "ortodoxa" faz parte desta lógica incipiente, desta religião que tem que marcar um rumo e uma visualização através da 
repetição. Desta mesma forma, "toma emprestado" em discurso, através desse jogo da memória, que atualiza ao Santo Daime como comunidade cristã.

Interessante destacar a análise feita por Marcio Goldman (1999) em torno à noção de pessoa, já que vemos nele uma tentativa particularista e relativista das noções de indivíduo, individualismo, pessoa, etc. vinculadas ao debate em torno a estas categorias tipicamente discutidas na antropologia e, usando suas expressões, fonte permanente de confusões. Goldman, refletindo sobre Foucault no mesmo aspecto que aqui foi tratado, no grande aporte de conhecimento histórico que Foucault faz e por tanto no exercício de discernimento que ele aporta, conclui de uma forma crítica e relativista com respeito ao uso das noções de individuo. Entendemos que o aporte de Goldman contribui na medida em que critica a Dumont no seu uso da idéia do individualismo como ideologia (Goldman, 1999). Aqui tentamos, justamente, trazer elementos que nos permitam ir em direção a este debate desde uma perspectiva que tente evitar a dicotomia ocidental que Goldman identifica na preocupação com o vínculo indivíduo-sociedade.

O desafio é pensar com Walter Mignolo como transitar outras margens que permitam novos olhares. Quando Mignolo afirma:

\footnotetext{
Habría otra posible tentación. Dudar de toda posibilidad comunitaria, puesto que después de todo la "comunidad" es una idea cristiana. Pensar de esta manera sería pensar que sólo la cristiandad está autorizada para pensar la comunidad, y que pensar la comunidad es, inevitablemente, pensar la cristiandad. Este tipo de razonamiento sería, en mi entender, un razonamiento que no puede salir de los "universales abstractos" y que cada palabra (comunidad, democracia, dignidad) es un significante vacío, en la racionalidad moderna, que se actualiza históricamente y al actualizarse, queda atrapado en su propia actualización. Lo que estoy proponiendo, en cambio, es pensar "comunidad" como un significante lleno y flotante que es, precisamente, una posibilidad de pensar la "fragmentación como proyecto universal" (Mignolo, 1998:9).
}

Devemos nos perguntar como estamos interpretando então estas idéias. Mais uma vez, o que acontece no Santo Daime é esse encontro de saberes do que viemos falando. O espaço foi criado para nos introduzir nestes percusros. Estas diferentes noções de comunidade das que fala Mignolo, estas diversas formas de aproximação ao indivíduo que nos ensina o texto do semiótico devem nos fazer pensar desde uma perspectiva de abrir novas formas de interpretação. Qual o resultado desse bricolage de tradições que convergem no Santo Daime? Aqui só tentamos começar a esboçar uma possibilidade narrativa que devemos continuar. Uma das direções marcadas para esse caminho vem do encontro, do choque desses espaços da morte. Aqui, essa explosão se 
vê representada pelo encontro do cristianismo com o que vem do funda da terra, o lugar onde as plantas crescem.

Em palavras de Antonio Benavides.

\footnotetext{
"Venho ensinando [Antonio] ao povo a revolução através de meu trabalho com as plantas" (Taussig, 1993:282).
}

\section{Referências}

BENJAMIN, Walter. "O narrador. Considerações sobre a obra de Nikolai Leskov". In: Magia e técnica, arte e política. Ensaios sobre Literatura e Historia da Cultura. São Paulo: Brasiliense, 1993.

BOURDIEU, Pierre. O poder simbólico. Rio de Janeiro: Bertrand, 1989.

DE CERTEAU, Michel. A invenção do cotidiano. Rio de Janeiro: Vozes, 1998.

DUMONT, Louis. O individualismo. Uma perspectiva antropológica da ideologia moderna. Rio de Janeiro: Rocco, 1985.

FOUCAULT, Michel. Historia da sexualidade 3: o cuidado de si. Rio de Janeiro: Graal, 1985.

GEERTZ, Clifford. O saber local. Novos ensaios em antropologia interpretativa. Rio de Janeiro: Vozes, 2003.

GOLDMAN, Marcio. "Uma categoria do pensamento antropológico: a noção de pessoa". In: Alguma antropologia. Rio de Janeiro: Relume-Dumará, 1999. p. 21-37.

HALBWACHS, Maurice. A memória coletiva. São Paulo: Centauro, 2004.

HERVIEU-LÉGER, Danièle. La religión, hilo de memória. Barcelona: Herder, 2005.

MACRAE, Edward. Guiado pela Lua. Xamanismo e uso ritual da ayahuasca no culto do Santo Daime. São Paulo: Brasiliense, 1992.

MAFFESOLI, Michel. O tempo das tribos. $O$ declínio do individualismo nas sociedades de massa. Rio de Janeiro: Forense universitária, 1998.

MIGNOLO, Walter. La revolución teórica del zapatismo: sus consecuencias históricas, éticas y políticas. In: Revista Orbis Tertius, ano 2, n. 5. La Plata: FaHCE/ UNLP, 1997. ORO, Ari. Na amazônia um messias de índios e brancos. Traços para uma antropologia do messianismo. Rio de Janeiro: Vozes, 1989.

SIMMEL, Georg. A filosofia da paisagem. Covilhã: Universidade da Beira Interior, 2009.

SOARES, Luiz Eduardo. "O Santo Daime no contexto da nova consciência religiosa". In: SOARES, L.E. O rigor da indisciplina. Ensaios de antropologia interpretativa. Rio de Janeiro: Relumé Dumará, 1994.

TAUSSIG, Michael. Xamanismo, Colonialismo e o Homem Selvagem. Um estudo sobre o terror e a cura. São Paulo: Paz e Terra, 1993.

VIVEIROS DE CASTRO, Eduardo. "Os pronomes cosmológicos e o perspectivismo ameríndio". In: Revista Mana, v.2, n.2. Rio de Janeiro: PPGAS/ UFRJ, 1996. p. 115144.

Recebido em: 22/12/2010

Aprovado em: 31/03/2011 